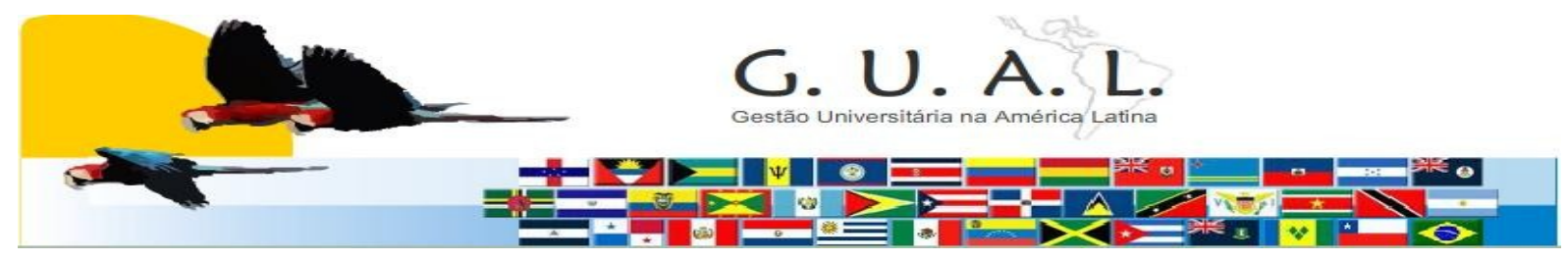

ISSN 1983-4535

Osvaldo Della Giustina, Especialista Universidade do Sul de Santa Catarina - UNISUL della_giustina@terra.com.br

\title{
ENSAIO
}

\section{Ciência, Tecnologia e Humanização da Sociedade a função da Universidade}

\section{0 processo civilizatório}

Neste inicio de século, ou de milênio, a humanidade, nós, estamos chegando a uma nova era, ou modo de ser da civilização. Ao afirmar isto não estou me referindo, propriamente, às profecias ou às aspirações dos místicos, aquarianos ou não.

Refiro-me a um imperativo histórico, determinado pelas transformações do modo de ser e agir da sociedade, condicionado agora pelos avanços da Ciência e da Tecnologia.

Se considerarmos que a transição de uma era pra outra, ou seja para um novo estagio civilizatório, é inerente ao processo histórico, se pode concluir, com segurança, que estamos vivendo um desses momentos. Abro um parêntese para definir que entendo por mudança civilizatória, a chegada ou a construção, de uma profunda transformação da estrutura, dos procedimentos, do conhecimento, dos valores, enfim, de todos os componentes de uma sociedade.

Há um certo consenso entre antropólogos e historiadores em geral, que pode ser considerada como uma primeira transição civilizatória a transformação do homem tribal, ou nômade, para o homem urbano, da organização de cidades e impérios; em seguida, deste estagio para uma organização mais descentralizada e distribuída - a era feudal; enfim, do estagio feudal para uma sociedade organizada e funcionando em torno do capital, conseqüência, entre outros fatores da descoberta da máquina a vapor, independentemente de ser o capital possuído por pessoas, grupos, sistemas e organizações, ou pelo Estado. Essas 
alternativas determinaram o surgimento do socialismo e do capitalismo, ambos fundamentados no capital, e não nas pessoas, ou na sociedade e seus componentes.

É importante identificar algumas características desse processo.

A primeira delas refere-se à aceleração das transformações que caracterizam essas mudanças. Enquanto no primeiro estagio a transformação se fez em milhares ou milhões de anos, no segundo estagio, aconteceu em alguns séculos e do mundo feudal para a organização industrial em um século, pouco mais ou menos.

Nesta evidencia histórica da aceleração das mudanças, é pertinente a afirmação de que uma nova era, a era pós-civilização industrial, se aproxima muito velozmente. Este é um imperativo histórico, não só pelo esgotamento do sistema do capital, ainda vigente, mas especialmente pelo surgimento de novos fatores de mudança, produzidos pelos avanços da Ciência e da Tecnologia.

A segunda característica refere-se ao fato de que as mudanças civilizatórias, no passado, não tem ocorrido simultaneamente nas diversas partes do mundo. É conseqüência desta característica, que mesmo neste inicio de milênio podem ser encontrados, povos, ou regiões que mal estão saindo da era das cavernas ou das civilizações tribais, em contraste com povos, ou regiões, que vivem na era industrial, ou já ultrapassando-a.

Uma terceira característica deve ser atribuída, enfim, ao surgimento de fatores específicos que preparam ou precipitam, a mudança civilizatória.

Assim, retornando à analise dos diversos estágios no primeiro estágio os fatores determinantes teriam sido o domínio do fogo e a descoberta do uso dos metais; a mudança da era dos grandes impérios para a organização feudal teria sido a difusão de novas teorias clássicas de organização social e, especialmente, no ocidente, a difusão do cristianismo e seus valores, mais do que propriamente as invasões dos povos periféricos; a transição da era feudal para a civilização do capital, enfim, teria sido conseqüência dos avanços da ciência e das artes renascentistas, que propiciaram a descoberta da máquina a vapor, as grandes descobertas e uma nova cultura, alem das novas teorias sociais decorrentes.

Considerado este ângulo, pode-se afirmar que nenhum dos fatores passados, tenham tido, em tão pouco tempo, a dimensão dos fatores científico-tecnológicos e de outras ordens, que estão impulsionando as transformações do atual processo civilizatório. Isto nos permite concluir que estamos, inevitavelmente, vivendo uma transformação civilizatória, da era 
industrial para uma nova era - essa era que necessito de contribuição da Universidade, para que tenhamos um mundo melhor.

\section{0 momento de transição}

A questão inicial é para onde esses fatores estão impulsionando a civilização?

Exemplificando a dimensão desses fatores, podem ser citados como surgidos no curto espaço do ultimo século, o radio, o telefone sem fio, o celular, o automóvel, o avião, o jato, o foguete espacial, a energia nuclear, o satélite, a nave espacial, a química fina, a nova engenharia, a engenharia genética, a eletrônica, a televisão, o computador, a internet e os serviços em rede, os shopping - center, as megalópoles, e o esvaziamento dos campos. Ainda, a explosão demográfica, os sistemas globalizados, a interdependência global, a economia concentrada. Dessa forma, a dimensão da Ciência e da Tecnologia, globalizando todas as coisas, somada à rapidez das mudanças, rompendo todas as fronteiras e, ainda, a velocidade da inovação transformada em processo continuo, nos permite dizer que a interpretação estática do mundo proposta por Parmenio, está sendo substituída pela visão dinâmica ou mutante proposta por Heráclito. Nos permite até especular se não estamos nos aproximando da superação das formas fundamentais do tempo e do espaço, propostas por Kant.

Este é o mundo atual, momento de transição, que vai nos levar à civilização da nova era, ou da pós-tecnologia, a um mundo melhor, ou, a que mundo.

A questão é que este processo em transição teima em manter a organização e o funcionamento da sociedade, baseados nos fundamentos da era industrial, ou seja, identificados, ou propostos, no século IXX, no tempo das tecnologias do trem de ferro, da maquina a vapor e de outros conhecimentos e tecnologias da época.

Afinal, O Capital, de Marx, ou a Riqueza das Nações, de Adam Smith, ou O Princípe, de Machiavel, foram escritos em meados daquele século. Os neo que se acrescentaram, tanto à visão socialista como à visão capitalista, não alcançaram trazer o processo á era das transformações trazidas pelo avanço ciência e da tecnologia.

Tal dissintonia tem produzido as crises que ameaçam esta fase de transição, crises que não se esgotam nos setores econômicos, ou financeiros. Elas abrangem a política, e ética individual e social, a estrutura da sociedade, aumentando a miséria de um lado, e a concentração da riqueza do outro, fazendo com que bilhões de pessoas e dezenas de países 
vivam, abaixo do nível de sobrevivência, enquanto a riqueza e o conhecimento se concentram, cada vez mais, nos sistemas que fogem em igual proporção às dimensões humanas.

Esse desequilíbrio constitui a ameaça deste momento de transição, ameaça que está aprofundando a desumanização do processo civilizatório, e sua transferência para o estágio civilizatório da era pós-tecnológica. Isto ocorrendo, as pessoas estarão submetidas a uma nova forma de totalitarismo, pior do que os que conhecemos no passado, ou ainda no presente, porque sem face, detentor de um poder incalculável, capaz de amortecer consciências, globalizar-se e massificar, ou robotizar o homem.

Esse processo de desumanização, porém, não pode ser atribuído aos avanços da ciência e da tecnologia em si. Ao contrario. Sob qualquer aspecto que se considere, seja o antropológico, o social, o personal, o ético ou espiritual, os avanços da ciência e da tecnologia poderiam ser fatores essenciais no processo de evolução da espécie humana, de quem são criaturas. No rumo em que estamos indo, estamos ameaçados de reviver a fabula do aprendiz de feiticeiro.

\section{As perspectivas da Ciência e da Tecnologia}

Nesta percepção, a ciência e a tecnologia utilizadas em favor da espécie humana, produziriam a era pós-tecnológicas efetivamente humanizada, isto é, organizada e funcionando em níveis harmônicos com o processo civilizatório e a evolução do homem ou seja, caminhando do ponto Alfa, primitivo, ao ponto Omega, pleno, na interpretação antropológica de Teilhard de Chardin. Enfim, a um mundo melhor.

A viabilidade desse novo processo, no entanto, tem como pressuposto a superação de fundamentos, valores, estruturas e procedimentos que continuam organizando - ou desorganizando a sociedade atual, como se disse.

Poderão essas teorias do século IXX, ainda que remendadas, continuar a ordenar o processo de transição, ou a civilização pós-tecnológica?

Mesmo que não possam, para que esse ordenamento seja possível não basta ultrapassá-las. É necessária a definição de novos instrumentos, ou teorias de organização social, que a organizem e a fundamentem com base em novos valores.

Ora esses valores, embora difusos e desordenados ai estão, compartilhados globalmente por pessoas e instituições, independentemente de raças, crenças, países, religiões, 
ideologias, ou outros componentes da realidade global: os direitos humanos, a paz, a justiça, o pluralismo, a preservação da natureza, a participação, a solidariedade e por ai adiante. É o conjunto desses valores que, em meu livro Participação e Solidariedade, defino como massa de consciência. Esta massa de consciência, embora difusa e desordenada, está a clamar pela consciência e competência das pessoas e instituições para que assumam o esforço de transformá-la em pratica. É preciso que se entenda isto, para que esse momento de transição e para que a sociedade pós - tecnológica, que está por vir, não aconteçam como fruto do acaso, de forma desordenada e caótica, ou simplesmente pela ruptura, de forma violenta, desumanizando o processo civilizatório, mas para que possamos viver e construir um mundo melhor.

\section{A Função das Universidades.}

$\mathrm{Na}$ resposta a este clamor está o desafio, especialmente das universidades e de seus intelectuais, e não só dos políticos e empresários, ou de outras categorias, pois as universidades e os intelectuais, que as constituem, são por definição produtores do conhecimento, da ciência e da tecnologia inovadoras.

Deve-se, ainda, acrescentar que, neste processo de transição, as universidades e seus cientistas, não podem se dedicar, apenas ou prioritariamente, à investigação ou ao desenvolvimento da ciência e da tecnologia das coisas. É preciso que se voltem a desenvolver a ciência e a tecnologia do homem e da sociedade, para que não se desumanize o processo civilizatório.

Na verdade, o que nos deve preocupar não é que a tecnologia, não continue avançando velozmente. Sei que esta afirmação poderá ser contestada, sob a alegação da necessidade de vencer a corrida competitiva. Mas há resposta, acaso, sobre para onde nos levará a corrida competitiva sem limites e, sobretudo, sem considerar o estágio da organização social, ou seja, o vagaroso ritmo como se transforma a sociedade? Para onde nos poderá levar esta disritmia?

Por isto, o que nos deve preocupar é o atraso das transformações sociais em relação aos avanços da tecnologia, ou seja, da ciência e da tecnologia da sociedade, em relação à ciência e à tecnologia das coisas.

Haverá caminhos para chegar a esta sociedade transformada, a sociedade sintonizada com os avanços da Ciência e Tecnologia, vez que a sociedade em que vivemos vive sob 
conceitos, ideologias, e teorias políticas econômicas e sociais da era pré - tecnológica? Afinal em que época viveram e formularam suas teorias Adam Schimit, Karl Marx ou Monteschieu?

Mas para tal tarefa não é suficiente o esforço isolado de algum pesquisador, de algum Mestre, de alguma bolsa de estudo conseguida com muito esforço, na Universidade, ou sabe Deus onde. É preciso que a Universidade, como Instituição, se volte e priorize o desenvolvimento da Ciência e da Tecnologia da organização social, que está atrasada em relação aos avanços da Ciência e da Tecnologia a que me referi como "das coisas".

É natural que surja a pergunta: o que fazer, por onde começar?

É preciso sim, que se considerem os mestres, cientistas, e líderes do passado.

Mas é preciso voltar - se para o presente e criar alternativas adequadas para as varias questões desse mundo pós tecnológico e para onde elas nos levam.

Pessoalmente - e eu não sou o único a procurar caminhos, após quase meio século de estudos, análises, perspectivas e propostas, publiquei o já referido livro PARTICIPAÇÃO E SOLIDARIEDADE: a Revolução do Terceiro Milênio, que julgo uma síntese de meu pensamento. Não me estendo aqui nem nas análises, nem nas propostas contidas no livro, mas nele, após analisar a inviabilidade de um mundo organizado, ou desorganizado, repito, pelos excessos da competição e da concentração sem limites, que geram a exclusão crescente e a desestruturação social - financeira, ética e cultural, reduzidas ao gosto dos sistemas globais, nele, dizia, proponho a Participação e Solidariedade, como fundamentos para organizar a nova era - o mundo mais humano, ou o mundo melhor. Viabillizar esses fundamentos é possível, ou seja, trazer os princípios éticos para transformá - los em instrumentos concretos é possível.

No entanto, afirma o livro que esses princípios, de dimensão ética só serão capazes de inspirar os novos modelos de organização e funcionamento da sociedade, na medida em que a desconcentração, ao invés da concentração e cooperação ao invés da competição se adotarem como esses instrumentos operacionais. Onde esta adoção ocorreu p. ex. da união Europeia, ou aqui em Sta. Catarina, em ambos os casos enquanto não forem destruídos, eles provaram que isto é possível.

A confirmação, ou não desta linha de investigação e o desenvolvimento de instrumentos coerentes para a organização e o funcionamento dessa Sociedade é o desafio que ponho à Universidade. É ela que, mais do que qualquer outra instituição, poderia gerar as 
teorias e os instrumentos operacionais nesta transição para um mundo melhor, de acordo com os valores e as aspirações da referida massa de consciência e para a qual não encontram resposta os que lideram em seu processo, presos à concepções, ideologias, normas e procedimentos do passado, da era pré - tecnológica. Ninguém lhes está oferecendo alternativas, nem nós que discordamos, e esta é a questão.

$\mathrm{Na}$ formulação desta linha de resposta e no gerar alternativas de instrumentalizá - la está a função da Universidade, na construção da um mundo melhor. Não creio que outra seja possível. 